\title{
Erratum to: Graphene Analogous Elemental van der Waals Structures
}

\author{
Oswaldo Sanchez, Joung Min Kim, and Ganesh Balasubramanian
}

\section{Erratum to:}

Chapter 4 in: G. Balasubramanian (ed.), Advances in Nanomaterials, DOI 10.1007/978-3-319-64717-3_4

Oswaldo Sanchez and Joung Min Kim affiliations were incorrect. The correct information is given below:

Department of Mechanical Engineering, Iowa State University, Black Engineering Building, Ames, IA 50011-2030, USA

\footnotetext{
The updated online version of this chapter can be found at https://doi.org/10.1007/978-3-319-64717-3_4

O. Sanchez $(\triangle)$ • J.M. Kim

Department of Mechanical Engineering, Iowa State University,

Black Engineering Building, Ames, IA 50011-2030, USA

e-mail: osanchez@iastate.edu

G. Balasubramanian

Lehigh University, Bethlehem, Pennsylvania, USA
} 